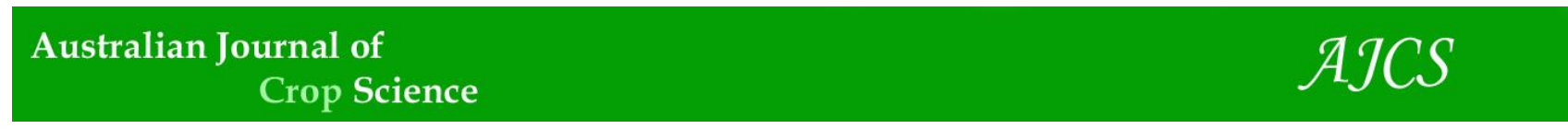

AJCS 10(6):874-877 (2016)

ISSN:1835-2707

DOI: 10.21475/ajcs.2016.10.06.p7593

\title{
Xylem ion balance in tomato plants under alkali stress
}

\author{
Huan Wang, Zhang He, Zhian Zhang", Chunwu Yang \\ Department of Agronomy, Jilin Agricultural University, Changchun 130118, Jilin Province, China
}

\author{
*Corresponding author: zhangzhian6412@163.com
}

\begin{abstract}
In many areas of China, alkalinity (high $\mathrm{pH}$ ) had strongly limit crops productivity. Control of ion loading into the xylem has been repeatedly named as a crucial factor determining plant salt tolerance. To investigate the role of roots in alkali tolerance of tomato, we tested the ion balance in root xylem of alkali stressed tomato plants. Two alkaline salts $\left(\mathrm{NaHCO}_{3}\right.$ and $\left.\mathrm{Na}_{2} \mathrm{CO}_{3}\right)$ were mixed in a 9:1 molar ratio as the alkali stress treatments. Under alkali stress condition or control condition, xylem sap samples were collected by cutting plant stems near to cotyledon vestige, and then all mineral elements in excreted xylem sap were measured. The results showed that alkali stress decreased the concentrations of $\mathrm{K}^{+}, \mathrm{Ca}^{2+}, \mathrm{Cl}^{-}$, and $\mathrm{NO}_{3}{ }^{-}$in the xylem sap, and increased $\mathrm{Na}^{+}$concentration, $\mathrm{Na}^{+} / \mathrm{K}^{+}$and $\mathrm{Na}^{+} / \mathrm{Ca}^{2+}$. Low alkali stress ( $\mathrm{pH} 8.6$ and $22.5 \mathrm{mM} \mathrm{Na}^{+}$) and strong alkali stress $\left(\mathrm{pH} 8.8\right.$ and $\left.45 \mathrm{mM} \mathrm{Na}^{+}\right)$have almost same $\mathrm{pH}$ but different $\mathrm{Na}^{+}$; however, under both stresses ion concentrations in the xylem sap were similar, indicating that the uptakes of inorganic ions were inhibited by high-pH but not by $\mathrm{Na}^{+}$.
\end{abstract}

Keywords: Xylem, Root, Ion balance, Alkali stress.

\section{Introduction}

There were 831 million hectares of soil in the world affected by salinization. Of this area, the soils with high-pH underlie 434 million hectares, while saline soils underlie 397 million hectares(Läuchli and Lüttge, 2002; Wang et al., 2008). Soil high-pH is an important environmental problems in some areas of the world. For example, in northeast China, $>70 \%$ of the grassland area is alkaline, sometimes with a soil $\mathrm{pH}>$ 10 (Kawanabe and Zhu, 1991). When a salinized soil contains $\mathrm{HCO}_{3}{ }^{-}$and/or $\mathrm{CO}_{3}{ }^{2-}$, which hike up the soil's $\mathrm{pH}$ consequentially, the plants are under damaging effects of both salt-stress and high-pH stress. However, relatively little attention has been given to alkali-stress or high-pH stress. In many areas of China, alkalinity (high $\mathrm{pH}$ ) had strongly limit crops productivity. Plants grown under salt stress condition generally were hurted by both osmotic stress and $\mathrm{Na}^{+}$injury (Munns and Tester, 2008; Zhu, 2003). Comparison of alkali stress with salt stress reveals an added high-pH effect due to alkali stress. High-pH may be a main reason why the injurious effect of alkali stress on plants is greater than that of salt stress at the same salinity. High-pH condition surrounding roots can lead to precipitates of mineral elements and induce nutrient deficiency (Wang et al., 2012; Yang et al., 2008a). Alkali tolerance of plants may involve many aspects: the processes of $\mathrm{pH}$ adjustments outside roots, osmotic regulation and controlling uptake and accumulation of $\mathrm{Na}^{+}$ and $\mathrm{K}^{+}$. Most studies of salt stress had focused osmotic regulation and ion balance (Munns and Tester, 2008; Zhu, 2003), however, a few study consider high $\mathrm{pH}$ stress. Wang et al. 2012 had reported that high $\mathrm{pH}$ of alkal stress limits the uptake and assimilation of nitrogen. In cases of some crops and halophytes, high $\mathrm{pH}$ of alkal stress stronly affect accumulation of $\mathrm{Na}^{+}$and $\mathrm{K}^{+}$(Yang et al., 2008a; Yang et al., 2008b; Yang et al., 2009). Insight into plant alkali stress tolerance may be important for undersdanding how plant adaptat in alklaine soil contains $\mathrm{HCO}_{3}{ }^{-}$and/or $\mathrm{CO}_{3}{ }^{2-}$. In this work, we tested the contents of nutrient ions form root xylem of alkali stressed-tomato plants, to investigate whether or how alkali stress affect uptake of nutrients in tomato plants.

\section{Results and Discussion}

\section{Alkali stressed reduced the availability of nutrient ions}

In this study, we analyzed the free activities of various ions in normal nutrition solution (labled as $0 \mathrm{mM}$ alkalinity), 15 and 30 alkali treatment solutions with the program GEOCHEM-PC 2.0. The calculated results revealed that the effects of alkali stress on free activities of $\mathrm{K}^{+}$and $\mathrm{NO}_{3}{ }^{-}$were slight, but alkali stress greatly precipitated phosphate and metal ions (except $\mathrm{K}^{+}$). Free activities of $\mathrm{K}^{+}$and $\mathrm{NO}_{3}^{-}$, principally depend on their activity coefficient, and the two ion are unable to be precipitated by $\mathrm{NaHCO}_{3}$ and/or $\mathrm{Na}_{2} \mathrm{CO}_{3}$. Figure 1 showed that, with increasing alkalinity, the activities of phosphate and metal ions decreased. The calculated results from GEOCHEM showed that alkali stress can decrease the activities of phosphate and metal ions, and reduced availability of nutrients surrounding roots.

\section{Alkali stressed limited the uptakes of nutrient ions}

Control o $\mathrm{f}$ ion loading into the xylem has been repeatedly named as a crucial factor determining plant salt tolerance. We found that alkali stress decreased flow of xylem sap, indicating that alkali stress may strongly inhibit the transportation of xylem sap from roots to stems (Fig. 2). To investigate whether or how alkali stress affect uptake of nutrients in tomato plants, we determined the concentrations of inorganic ions in the root xylem sap of alkali stressed 

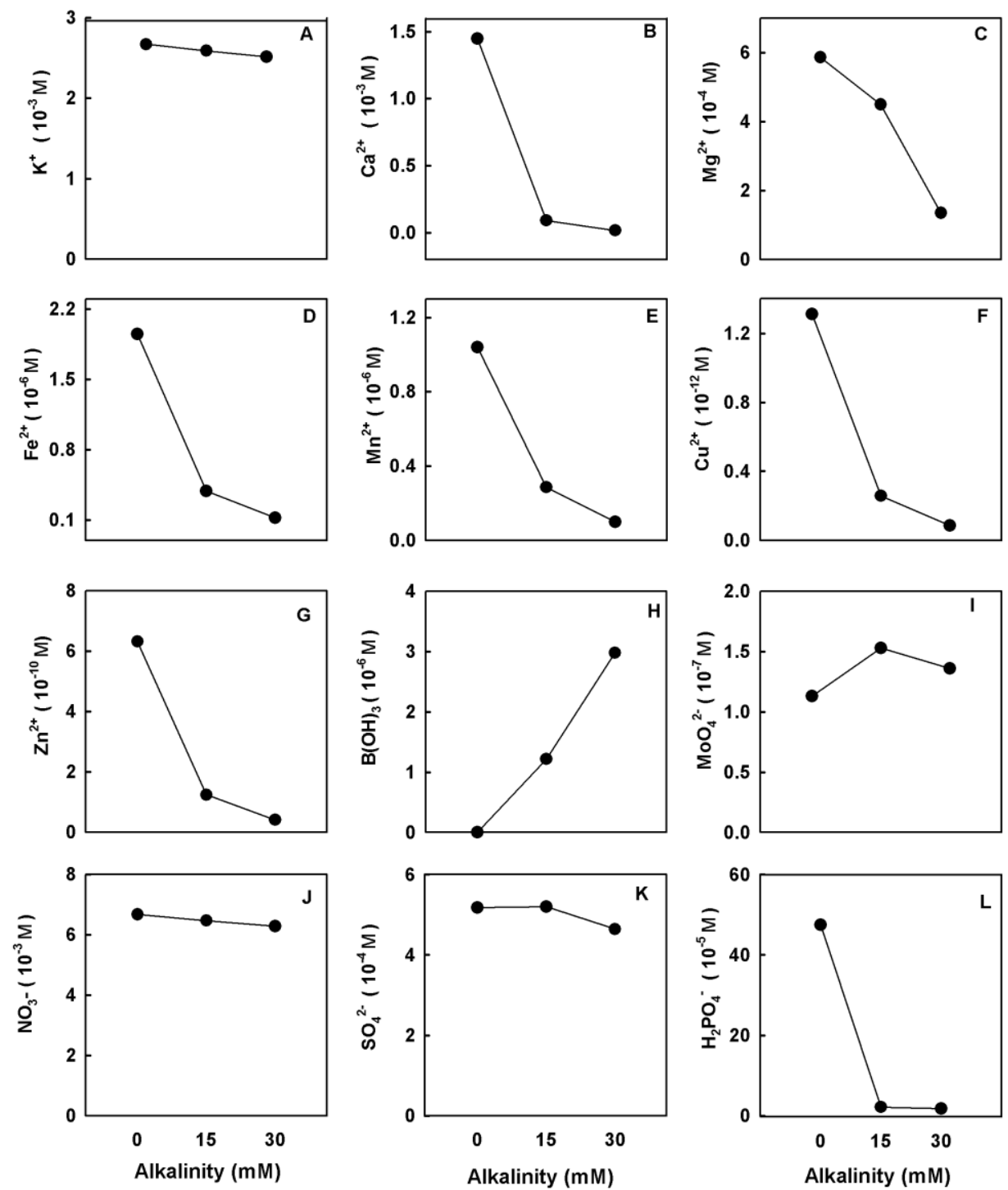

Fig 1. Effects of alkali stress on the free activities of various ions in nutrient solution. . Two alkaline salts $\left(\mathrm{NaHCO}_{3}: \mathrm{Na}_{2} \mathrm{CO}_{3}\right)$ were mixed in a 9:1 molar ratio as the alkali stress treatments. The free activities of various ions in normal nutrition solution (labled as 0 $\mathrm{mM}$ alkalinity), 15 and 30 alkali treatment solutions were were analyzed with the program GEOCHEM-PC 2.0.

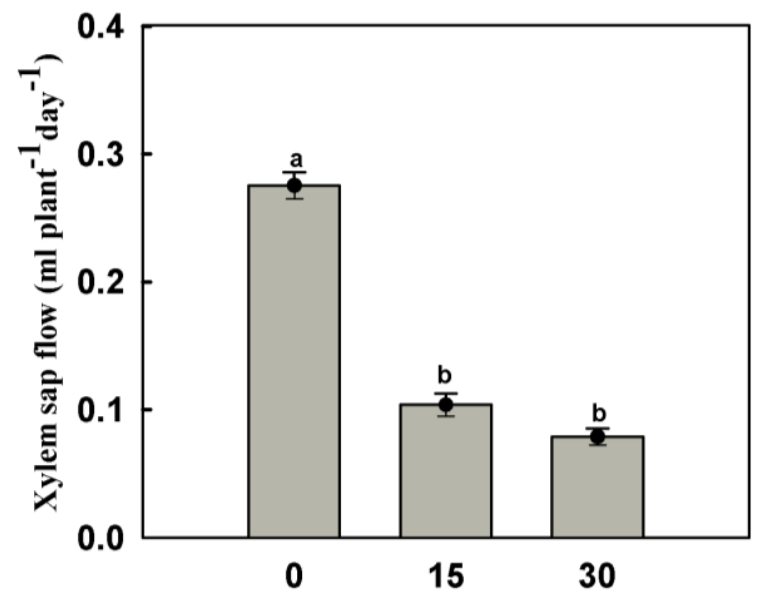

Alkalinity (mM)

Fig 2. Effects of alkali stress on flow of xylem sap in tomato plants. The values are means $( \pm$ SE) of four replicates. Means followed by different letters in the same curve are significantly different at $P \leq 0.05$, according to Student-Newman-Keuls (q test). 


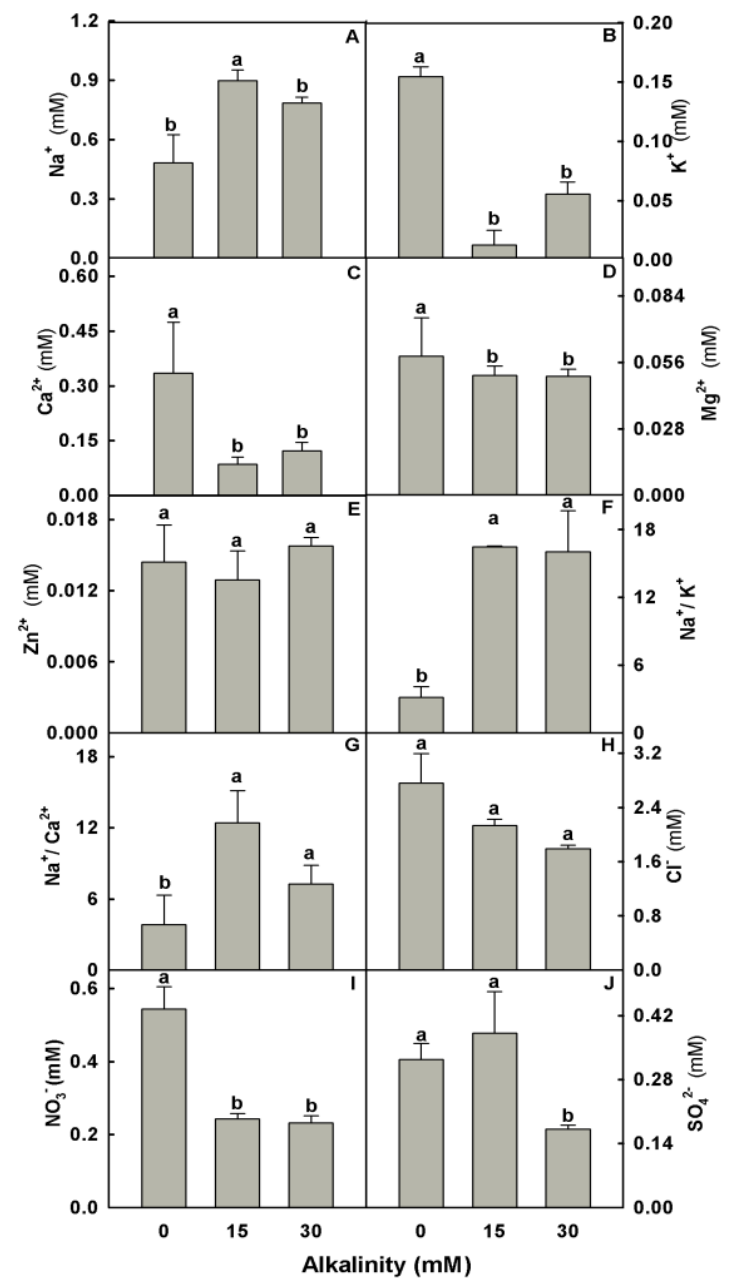

Fig 3. Concentrations of inorganic ions in the root xylem sap of tomato plants under alkali stress. The values are means $( \pm$ SE) of four replicates. Means followed by different letters in the same curve are significantly different at $P \leq 0.05$, according to Student-Newman-Keuls (q test).
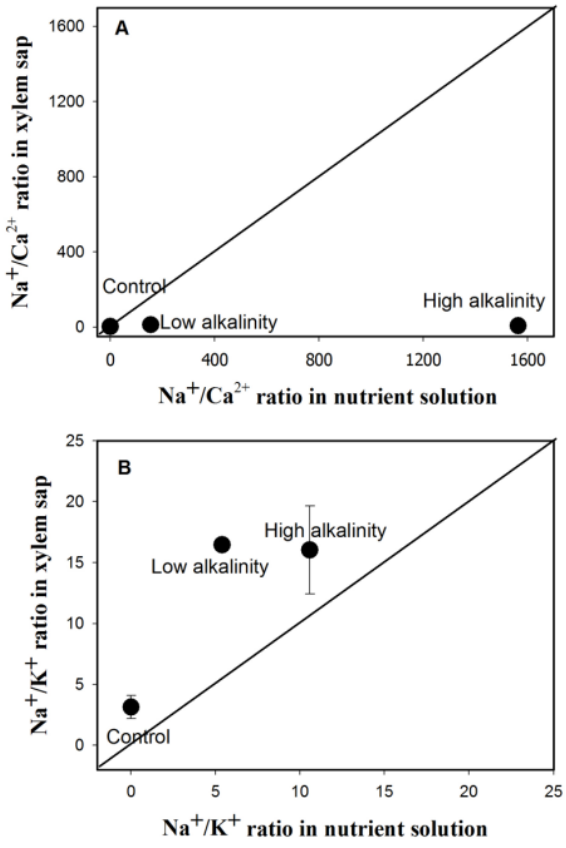

Fig 4. Ion balance in the xylem sap of tomato plants under stress. A, the ratio of $\mathrm{Na}^{+}$and $\mathrm{Ca}^{2+}$ free activities in nutrient solution is plotted against the $\mathrm{Na}^{+} / \mathrm{Ca}^{2+}$ ratio in xylem sap. B, the ratio of $\mathrm{Na}^{+}$and $\mathrm{K}^{+}$free activities in nutrient solution is plotted against the $\mathrm{Na}^{+} / \mathrm{K}^{+}$ratio in xylem sap. 
tomato. The results revealed that both 15 and $30 \mathrm{mM}$ alkali stresses decreased the concentrations of $\mathrm{K}^{+}, \mathrm{Ca}^{2+}, \mathrm{Cl}^{-}$, and $\mathrm{NO}_{3}{ }^{-}$in the xylem sap , and increased $\mathrm{Na}^{+}$concentration, $\mathrm{Na}^{+} / \mathrm{K}^{+}$and $\mathrm{Na}^{+} / \mathrm{Ca}^{2+}$ (Fig. 3). Alkali stress also broke the balances between $\mathrm{Na}^{+}$and $\mathrm{K}^{+}$as well as $\mathrm{Na}^{+}$and $\mathrm{Ca}^{2+}$. Under control condition, both $\mathrm{Na}^{+} / \mathrm{K}^{+}$and $\mathrm{Na}^{+} / \mathrm{Ca}^{2+}$ in xylem sap were similar to that of nutrient solution (Fig. 4). However, under alkali stress, $\mathrm{Na}^{+} / \mathrm{K}^{+}$ratio was higher in xylem sap than in nutrient solution, while ratio of $\mathrm{Na}^{+} / \mathrm{Ca}^{2+}$ was much lower in xylem sap than in nutrient solution (Fig. 4). It is well known that mineral ion uptake and $\mathrm{Na}^{+}$exclusion in higher plants relies on the transmembrane $\mathrm{H}^{+}$gradient achieved by $\mathrm{H}^{+}$-ATPase or other proteins (Munns and Tester, 2008; Rubinigg et al., 2005; Shabala and Cuin, 2007). Under alkali stress, lack of external $\mathrm{H}^{+}$might break transmembrane $\mathrm{H}^{+}$ gradient of roots, possibly reducing exclusion of $\mathrm{Na}^{+}$into rhizosphere and limiting mineral uptake. This may be the basis of alkali injury. Our results supported this point. We found that high-pH inhibited uptake of most inorganic ions. Although low alkali stress ( $\mathrm{pH} 8.6$ and $22.5 \mathrm{mM} \mathrm{Na}^{+}$) and strong alkali stress ( $\mathrm{pH} 8.8$ and $45 \mathrm{mM} \mathrm{Na}^{+}$) showed almost same $\mathrm{pH}$ but different $\mathrm{Na}^{+}$, under both stresses the concentrations of inorganic ions in the xylem sap were similar, indicating that the uptakes of inorganic ions were inhibited by high-pH but not by $\mathrm{Na}^{+}$. In addition, we observed that alkali stress did not reduce free activities of $\mathrm{K}^{+}$ and $\mathrm{NO}_{3}^{-}$, but greatly decreased their concentration in xylem sap, which may be because lack of external $\mathrm{H}^{+}$caused by alkali stress may limit the uptakes of $\mathrm{K}^{+}$and $\mathrm{NO}_{3}{ }^{-}$.

\section{Materials and Methods}

\section{Plant materials and stress treatment}

Seeds of tomato (Lycopersicon esculintum Mill) were provided by the Institute of Genetics and Cytology of Northeast Normal University, China. Seeds were sown in $17-\mathrm{cm}$ diameter plastic pots containing $2.5 \mathrm{~kg}$ of washed sand. Each pot contained 5 seedlings which were sufficiently watered with 0.5 fold Hoagland nutrient solution every day. All pots were placed in a greenhouse $\left(25 / 19^{\circ} \mathrm{C}\right.$ and $16 / 8 \mathrm{~h}$ of day/night, light at $500 \mu \mathrm{mol} \mathrm{m} \mathrm{m}^{-2} \mathrm{~s}^{-1}$ ). When the seedlings were 3 weeks old, stress treatments were performed once every day with the application of nutrient solutions containing the appropriate stress salts. Control plants were watered with nutrient solution. Two alkaline salts were mixed in a 9:1 molar ratio $\left(\mathrm{NaHCO}_{3}: \mathrm{Na}_{2} \mathrm{CO}_{3}\right.$ as the alkali stress treatments. Total salt concentrations were set at 15 and 30 $\mathrm{mM}$. The stress treatment duration was 3 days.

The free activities of various ions in normal nutrition solution (labled as $0 \mathrm{mM}$ alkalinity), 15 and 30 alkali treatment solutions were analyzed with the program GEOCHEM-PC 2.0. (Parker et al. 1987).

\section{Xylem sap and ion determination}

Xylem sap samples were collected by cutting plant stems near cotyledon vestige (Shabala et al., 2010). The resultant excreted xylem sap was immediately collected with amicropipette and stored (Shabala et al., 2010). For each treatment, excreted xylem sap of 6-10 plants were pooled as a biological replication. In this study, four biological replications were performed. The contents of $\mathrm{NO}_{3}^{-}, \mathrm{Cl}^{-}$, $\mathrm{H}_{2} \mathrm{PO}_{4}^{-}$, and $\mathrm{SO}_{4}{ }^{2-}$ in xylem sap were determined by ion chromatography (DX-300, DIONEX, Sunnyvale, USA). An inductively coupled plasmaatomic emission spectrometer (ICP-AES) was used to measure the contents of $\mathrm{K}, \mathrm{Na}, \mathrm{Ca}$,
$\mathrm{Mg}, \mathrm{Fe}, \mathrm{Mn}, \mathrm{Cu}, \mathrm{Zn}, \mathrm{B}, \mathrm{Mo}$ and $\mathrm{P}$ in xylem sap.

\section{Statistical analysis}

We perform statistical analysis of the data using SPSS 13.0 (SPSS, Chicago, USA). All data were an average of the four replicates. Statistical significance was determined by Student-Newman-Keuls test at 0.05 level.

\section{Conclusion}

The calculated results from GEOCHEM showed that alkali stress can decrease the activities of phosphate and metal ions. As a result, the availability of nutrients surrounding the roots were reduced. Under alkali stress, lack of external $\mathrm{H}^{+}$might break transmembrane $\mathrm{H}^{+}$gradient of roots, may limit exclusion of $\mathrm{Na}^{+}$into rhizosphere and limiting mineral uptake. Our results also showed that the uptakes of inorganic ions may be inhibited by high-pH but not by $\mathrm{Na}^{+}$.

\section{Acknowledgments}

This study was supported by ,13th five-year science and technology research project of the education department of Jilin Province( 2016195),initial funding of Jilin Agricultural University (2015008) and the National Natural Science Foundation of China Project (No. 31300192).

\section{References}

Kawanabe S, Zhu T (1991) Degeneration and conservational trial of Aneurolepidium chinense grassland in Northern China. J Jap Grassl Sci. 39: 91-99.

Läuchli A, Lüttge U (2002) Salinity: Environmentplants-molecules. Boston: Boston Kluwer Academic Publishers.

Munns R, Tester M (2008) Mechanisms of salinity tolerance. Annu Rev Plant Biol. 59: 651-681.

Parker D, Zelazny L, Kinraide T (1987) Improvements to the program GEOCHEM. Soil Sci Soc Am J. 51: 488-491.

Rubinigg M, Posthumus F, Elzenga J, Stulen I (2005) Effect of $\mathrm{NaCl}$ salinity on nitrate uptake in Plantago maritima L. Phyton. 45: 295-302.

Shabala S, Cuin TA (2007) Potassium transport and plant salt tolerance. Physiol Plantarum. 133: 651-669.

Shabala S, Shabala S, Cuin TA, Pang J, Percey W, Chen Z, Conn S, Eing C, Wegner LH (2010) Xylem ionic relations and salinity tolerance in barley. Plant J. 61: 839-853.

Wang H, Ahan J, Wu Z, Shi D, Liu B, Yang C (2012) Alteration of nitrogen metabolism in rice variety 'Nipponbare' induced by alkali stress. Plant Soil. 355: 131-147.

Wang Y, Ma H, Liu G, Xu C, Zhang D, Ban Q (2008) Analysis of gene expression profile of Limonium bicolor under $\mathrm{NaHCO}_{3}$ stress using cDNA microarray. Plant Mol Bio Rep. 26: 241-254.

Yang C, Shi D, Wang D (2008a) Comparative effects of salt and alkali stresses on growth, osmotic adjustment and ionic balance of an alkali-resistant halophyte Suaeda glauca (Bge.). Plant Growth Regul. 56: 179-190.

Yang C, Wang P, Li C, Shi D, Wang D (2008b) Comparison of effects between salt-stress and alkali-stress on the growth and photosynthesis of wheat. Photosynthetica. 46:107-114.

Yang C, Zhang M, Liu J, Shi D, Wang D (2009). Effects of buffer capacity on growth, photosynthesis, and solute accumulation of a glycophyte (wheat) and a halophyte (Chloris virgata). Photosynthetica. 47: 55-60

Zhu JK (2003) Regulation of ion homeostasis under salt stress. Curr Opin Plant Bio. 6: 441-445. 